\title{
User Resistance of Mobile Banking in China: Focus on Perceived Risk
}

\author{
Shuang Cheng ${ }^{1}$, Sang-Joon Lee ${ }^{1}$ and Kyeong-Rak Lee ${ }^{2}$ \\ ${ }^{1}$ Graduate School of Business Administration, Chonnam National University, \\ Yongbong-dong, Buk-gu, Gwangju, 500-757, Korea \\ shuang87512@hotmail.com,s-lee@chonnam.ac.kr \\ ${ }^{2}$ Free $21+e$-Service Team, Interdisciplinary Program of Electronic Commerce, \\ Chonnam National University, Yongbong-dong, Buk-gu, Gwangju, 500-757, Korea \\ kryi0807@chonnam.ac.kr
}

\begin{abstract}
Although there are many studies on the adoption intentions for smartphone-based mobile banking, there is no apparent effect on the popularity of it. This is because the smartphone users have a resistance to innovation on mobile banking. The purpose of this study is to identify and analyze the relationship between user resistance and different factors from innovation and user's characteristics. Thereafter, important factors are identified which mainly affect/determine user resistance to mobile banking. Survey research of this study was conducted around university undergraduates, graduate students, and employees in Henan of China. The results of this study are as follows. Social Influence and Perceived Complexity have positive effect on Perceived Risk, and Trust has negative effect on Perceived Risk, Perceived Security and Perceived Protection of Private information have no effect on Perceived Risk. Perceived Risk has positive effect on User Resistance.
\end{abstract}

Keywords: Mobile Banking, Perceived Risk, User Resistance

\section{Introduction}

In 2012, China overtook the United States to become the world's largest global smartphone market in terms of shipment. In that year, smartphone shipments in China were estimated to have reached 208 million units, accounting for almost 21 percent of the entire global smartphone market share. By the end of 2012, the number of smartphone users in China had reached 380 million, smartphone sales to end users were also reaching new levels, with sales around 169 million units sold in total that year [1]. The number of mobile banking users in China reached 150 million in 2012, accounting for more than $40 \%$ of mobile banking users worldwide. Major commercial banks saw more than $100 \%$ growth in mobile banking users in 2012, and more than 300\% growth in mobile banking transaction value [2].

Innovation is a key factor for companies to survive and grow in the long run [3], and has been called as the lifeblood of most organization [4] especially in the dynamic \& complex markets, and uncertain economic circumstances [5]. One of the main reasons for inhibiting or delaying the innovation diffusion is consumers ${ }^{\text {ee }}$ resistance, which appears to have been neglected in the academic literature [6].

Consumers' resistance plays an important role in the success of innovation, as it can certainly inhibit or delay the consumer adoption. It has been termed as one of the major causes for market failure of innovations [6] and also a valuable source of information vital to the successful implementation and marketing of innovation [7]. If the resistance cannot be 
broken down, adoption slows down, and the innovation is likely to fail [6]. Firms need to understand consumers' resistance, its reasons, and influencing factors; in order to become much more efficient in their improvement efforts, and to identify ways to improve competitiveness, productivity, and profitability [8].

The purpose of this study is to identify and analyze the relationship between user resistance and different factors from innovation and user's characteristics. Thereafter, important factors are identified which mainly affect/determine user resistance to mobile banking. Moreover, the inter-relationship among the selected factors is found out, to know the effect of each factor on other factors. Perceived risk is a major factor which influences user's resistance behavior to smartphone-based mobile banking. So if we want to know the reasons why people don't use smartphone-based mobile banking, we have to know which factors will influence consumer's perceived risk.

The significance of this study is that financial institutions and telecommunications companies of China could potentially establish new and more accurate strategies based on the resistance factors identified in this study to gain more profits.

\section{Literature Review}

An innovation is "an idea, practice, or object that is perceived as new by an individual or other unit of adoption" [9]. Innovation resistance is consumers' reaction towards an innovation, either because it create potential changes from a satisfactory status quo or because it is in conflict with their belief structure [10]. One aspect of innovation resistance is; resistance due to changes imposed by innovation and is called resistance to change [11]. Zaltman and Duncan (1977) defined this as "any conduct that serves to maintain the status quo in the face of pressure to alter the status quo". Resistance to change is a natural response of a human being to any changes that disturb the balance of living environment or firms' actions [12]. As for innovation resistance, "it is not an innovation per se that people resist but the changes associated with it" [13]. This creates the postulation of pro-change bias, which means that every innovation is excellent and everyone must implement/adopt it, because success of innovation is inevitable [8].

Innovation Resistance is not the obverse of Innovation Adoption. Adoption begins only after the initial resistance offered by the consumers is overcome. Thus, it is the Resistance perspective which looks at what happens to the innovation since the time it is conceived. Resistance would seem to be a normal response of consumers when confronted with innovations [14]. The concept of innovation resistance was presented by Sheth (1981) as the "less developed concept" in diffusion research. He researched psychology of innovation resistance and proposed two psychological constructs which seems very useful in understanding the psychology of innovation resistance. These psychological constructs are; habit/behavior towards existing products and perceived risks associated with innovation adoption. He claimed that the perceived risk increased user resistance to innovation [15].

There is also a social influence on consumers' perception, which is affected by the social perception of information technology. According to Kim et al. (2008), a positive review by a third party can have a positive impact on one's perceived risks of electronic commerce (ecommerce) [16]. Similarly, a negative social perception can have an equally strong impact on consumer trust in mobile banking, especially with respect to various security issues that pose the greatest concerns in using mobile banking services.

Perceived security is the belief that the online vendors will fulfill the security requirements (authentication, integrity, encryption, etc.,). Monetary transactions in particular such as mobile banking require a wide range of security measures, and security assurance has become increasingly more important with wider use of mobile banking services [17]. In terms of e- 
commerce, the perceived protection of private information is the perception of consumers regarding the extent to which their private or personal information is protected by the online vendors. This means that consumers will perceive greater risks if a system for protection of private information is not well-established by the vendors [16].

Perceived complexity is how complex or difficult it is for users to understand and use the innovation. Some innovations are easily and quickly grasped by individuals and the potential user group, whereas others are more difficult to comprehend and thus their utilization occurs more slowly. Complexity is a concept that can be viewed as a counterpart to usefulness and convenience of use proposed by TAM [18].

Trust is even more important in an online environment. The reason for this is that the tasks are executed by computers through the use of technology such as the Internet, which may cause a conflict with the trust in the organization, and trust is associated with virtual organization. Trust is a variable that has been verified as a factor influencing perceived risks in an online environment in multiple studies [19].

\section{Research Methodology}

In order to test the hypothesis, a survey was conducted with students and employees in Henan of China as the subjects. In the questionnaire, the measurement items for the variables were measured based on a 5-point Likert scale, and the measurement items for the variables were proven to be reliable and valid in preceding studies and were adjusted accordingly to suit this particular study.

\subsection{Research Hypothesis}

Based on the literature reviews above, we formulate the hypothesis as follows:

H1 : Social Influence(SI) has a positive relationship with Perceived Risk.

H2 : Perceived Security (PS) has a negative relationship with Perceived Risk.

H3 : Perceived Protection of Private information(PPP) has a negative relationship with Perceived Risk.

H4 : Perceived Complexity (PC) has a positive relationship with Perceived Risk.

H5 : Trust(TR) has a negative relationship with Perceived Risk.

H6 : Perceived Risk (PR) has positive relationship with User Resistance(UR).

\subsection{Data Collection and Analysis}

In order to test the hypothesis, a survey was conducted with students and employees in Henan of China as the subjects. The demographic characteristics of the sample population were as follows. Of the 200 respondents, 110 (55.0\%) were male and 90 (45.0\%) were female. With respect to age, $190(95.0 \%)$ were under the age of 30 and $10(5.0 \%)$ were over the age of 30. With respect to occupation, 56 (26.0\%) were employed, $125(62.5 \%)$ were students, and 19 (9.5\%) responded 'other'.

In this study, the reliability of multi-item scale was measured by determining the Cronbach's $\alpha$. The $\alpha$ coefficients for all the measurement variables in this study were calculated to be higher than 0.8 with high internal consistency, based on which it can be determined that the scale was highly reliable.

The reliability of the questionnaire used in this study was measured by factor analysis. For the factor analysis, factors with an eigenvalue, signifying the amount of dispersion explained by the factor of 1 and higher were selected. The factor loadings of all items were above 0.7. Therefore, the validity of the measurement tool can be seen that there is no problem. 
Before performing a regression analysis to test the hypothesis, Pearson's correlation analysis was conducted to identify the correlation between the variables and their descriptive statistics. According to the results of correlation analysis, there was a significant correlation that was consistent with the direction predicted in the hypothesis.

In order to verify the factors influencing perceived risks, social influence, perceived security, perceived protection of private information, trust and perceived complexity were set as independent variables and the perceived risks as a dependent variable for a multiple regression analysis. The results of a regression analysis of the independent variables and the dependent variable are shown in Table 1 and Table 2.

Table 1. Regression Analysis

\begin{tabular}{lllllll}
\hline $\begin{array}{l}\text { Dependence } \\
\text { Variable }\end{array}$ & $\begin{array}{l}\text { Independence } \\
\text { Variable }\end{array}$ & Beta & $\mathrm{T}$ & P-value & Tolerance & VIF \\
\hline & (constant) & .444 & 7.220 & .000 & .852 & 1.173 \\
& SI & .032 & .490 & .625 & .762 & 1.313 \\
PR & PS & -.113 & -1.799 & .074 & .817 & 1.223 \\
& PPP & .202 & 3.302 & .001 & .858 & 1.165 \\
& PC & -.195 & -3.259 & .001 & .895 & 1.117 \\
& TR & & $\mathrm{F}=23.279$ & p-value $=0.000$ & \\
\hline $\mathbb{R}^{2}=0.375$ & Revised $\mathbb{R}^{2}=0.359$ & & &
\end{tabular}

The results of the multiple regression analysis with respect to the regression coefficient (beta) of each of the independent variables are as follows: regression coefficient (beta) for social influence was a significant positive value of $0.444(\mathrm{p}=0.000)$; perceived security, an insignificant value of $0.032(\mathrm{p}=0.625)$; perceived complexity, a significant positive value of $0.202(\mathrm{p}=0.001)$; perceived protection of private information, an insignificant value of -0.113 $(\mathrm{p}=0.074)$; and trust, a significant negative value of $-0.195(\mathrm{p}=0.001)$. Based on these results, it can be determined that the perceived risks increase at higher social influence and perceived complexity, and lower trust. With respect to the degree of the influence of the selected factors on the perceived risks, social influence had the greatest influence, followed by perceived complexity and trust. These results support hypotheses 1, 4 and 5 .

Table 2. Regression Analysis

\begin{tabular}{lllllll}
\hline $\begin{array}{l}\text { Dependence } \\
\text { Variable }\end{array}$ & $\begin{array}{l}\text { Independence } \\
\text { Variable }\end{array}$ & Beta & $\mathrm{T}$ & P-value & Tolerance & VIF \\
\hline UR & (constant) & & 6.628 & .000 & & \\
\hline$R^{2}=0.169$ & Revised $R^{2}=0.165$ & .411 & 6.348 & .000 & 1.000 & 1.000 \\
\hline
\end{tabular}

The result of the regression analysis showed that the regression coefficient (beta) for perceived risks, which was the independent variable, was a significant positive value at 0.411 $(\mathrm{p}=0.000)$, based on which it can be determined that higher the perceived risks, the higher the user resistance. This result supports hypothesis 6 .

\section{Implications}

First, in order to minimize the negative social influence on perceived security, in addition to reinforcing and supplementing the security measures from the technical aspect, the banks is needed to understand that it is highly effective to actively advertise and promote the level of security they provide and to dispel the common social concerns regarding the security issues related to mobile banking services. Also, they should establish a strict and thorough security 
policy and make their customers aware of the fact that there are low risks associated with mobile banking.

Second, it was determined during this study that many consumers perceive the authentication procedure for security to be quite complex. This suggests that it is necessary for banks to implement simpler log-in and authentication procedures, under the premise that this does not reduce the level of security. Also, they need to engage in aggressive advertising and promotional campaigns to make users realize that mobile banking is not as complex as they may think.

Third, trust in smartphone-based mobile banking is negatively correlated with perceived risks. Thus, banks need to produce advertisements and promotional materials that inform the users of the accuracy and reliability of mobile banking as a means to minimize the perceived risks.

\section{References}

[1] Smartphone market in China, www.statista.com, (2013).

[2] H. Zhang, "Mobile banking trends in china", Industry trends, (2013).

[3] J. Tidd, "Innovation management in context: environment, organization and performance", International Journal of Management Reviews, vol. 3, no. 3, (2001), pp. 169-183.

[4] R. Balachandra and J. H. Friar, "Factors for Success in R\&D Projects and New Product Innovation: A Contextual Framework", IEEE Transactions on Engineering Management, vol. 44, (1997) August, pp. 276287.

[5] M. Assink, "Inhibitors of disruptive innovation capability: a conceptual model", European Journal of Innovation Management, vol. 9, (2006), pp. 215-233.

[6] S. Ram, "Successful innovation using strategies to reduce consumer resistance: an empirical test", Journal of Product Innovation Management, vol. 6, no. 1, (1989), pp. 20-34.

[7] E. O'Connor, P. Charles, L. Robert and H. David, "Implementing New Technology: Management Issues and Opportunities", The Journal of High Technology Management Research I (I), (1990), pp. 68-89.

[8] S. Dunphy and P. A. Herbig, "Acceptance of innovations: The customer is the key!", The Journal of High Technology Management Research, vol. 6, no. 2, (1995), pp. 193-209.

[9] E. M. Rogers, "Diffusion of Innovations", 4th ed., The Free Press, New York, NY, (1995).

[10] S. Ram and N. J. Sheth, "Consumer resistance to innovation: The marketing problem and its solution", The Journal of Consumer Marketing, vol. 6, no. 2, (1989), pp. 5-14.

[11] H. Gatignon and T. S. Robertson, "Technology diffusion: an empirical test of competitive effects", Journal of Marketing, vol. 53, (1989), pp. 35-49.

[12] G. Zaltman and R. Duncan, "Strategies for Planned Change”, Wiley, New York, NY, (1977).

[13] E. H. Schein, "Organizational Culture and Leadership", Jossey-Bass, San Francisco, CA, (1985).

[14] S. Ram, "A model of innovation resistance", Advances in Consumer Research, vol. 14, no. 1, (1987), pp. 208-213.

[15] J. N. Sheth, "Psychology of innovation resistance: the less developed concept", Research in Marketing, vol. 4, no. 3, (1981), pp. 273-283.

[16] D. J. Kim, D. L. Ferrin and H. R. Rao, "A trust-based consumer decision-making model in electronic commerce: The role of trust, perceived risk, and their antecedents", Decision support systems, vol. 44, no. 2, (2008), pp. 544-564.

[17] F. Buellingen and M. Woerter, "Development perspectives, firm strategies and application in mobile commerce”, Journal of Business Research, vol. 57, no. 21, (2004), pp. 1402-1408.

[18] L. Tornatzky and K. Klein, "Innovation Characteristics and Innovation Adoption Implementation: A MetaAnalysis of Findings", IEEE Transaction on Engineering Management, vol. 29, no. 1, (1982), pp. 28-45.

[19] P. A. Pavlou, "Consumer Acceptance of Electronic Commerce - Integrating Trust and Risk, with the Technology Acceptance Model”, International Journal of Electronic Commerce, vol. 7, no. 3, (2003), pp. 69103. 


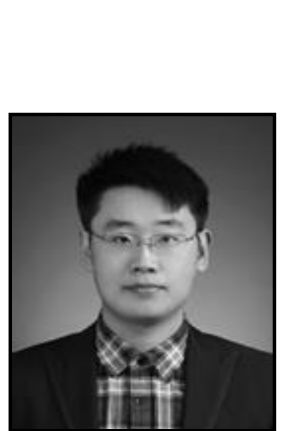

\section{Authors}

Shuang Cheng, he received the BE degree in Materials Science and Engineering from Henan Polytechnic University, and Master of E-commerce degree in Interdisciplinary Program of Electronic Commerce from Chonnam National University. Since 2013, He has been a Ph.D. student in the Graduate School of Business Administration of Chonnam National University. His research interests include EC, MIS and IT Service.

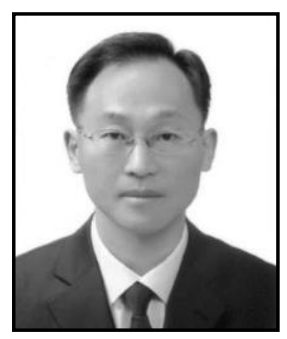

Sang-Joon Lee, he received the BS, MS and Ph.D. degrees in Computer Science and Statistics from Chonnam National University. He was assistant professor in Seonam University and Shingyeong University. Since 2007, He has been with Chonnam National Univ. as an associate professor in the School of Business Administration. His research interests include MIS, SE, IT Service and Ubiquitous Business.

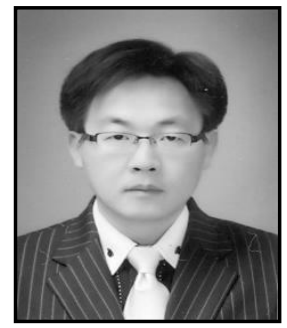

Kyeong-Rak Lee, he received the BA degree in MIS from Kookmin University, MS degree in Electronic Commerce, Chonnam National University, Ph.D. degree in Business Administration, Chonnam National University. He works for Free21+ e-Service Team, Interdisciplinary Program of Electronic Commerce, Chonnam National University, Korea. 